(a)

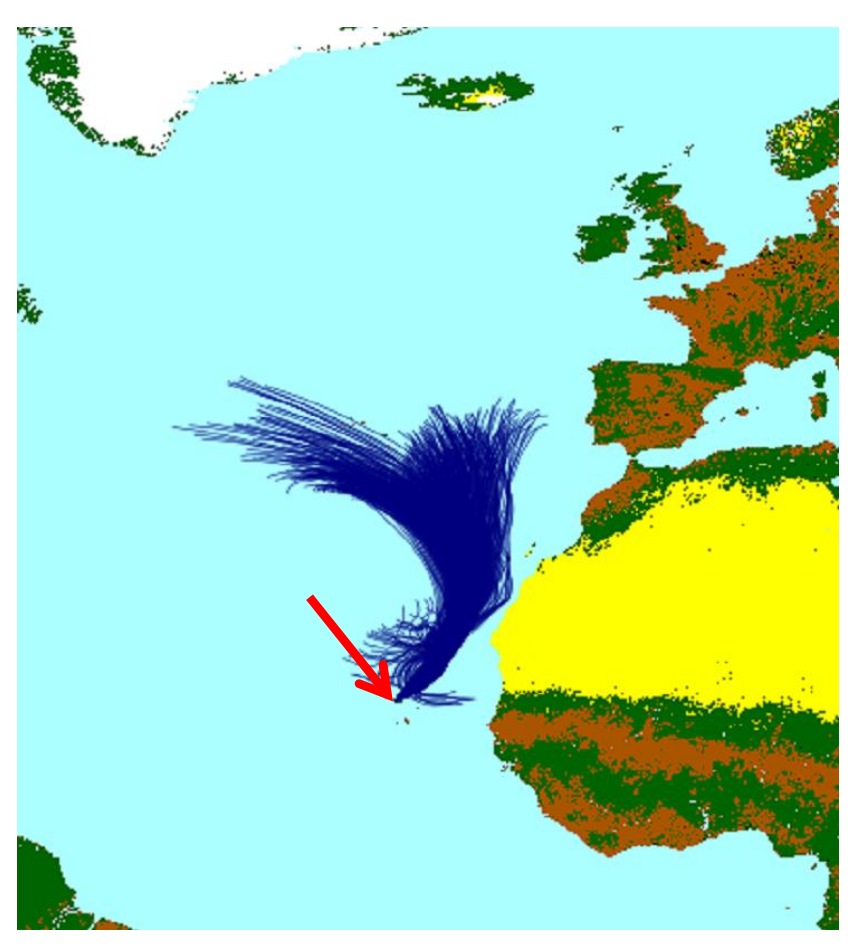

(b)

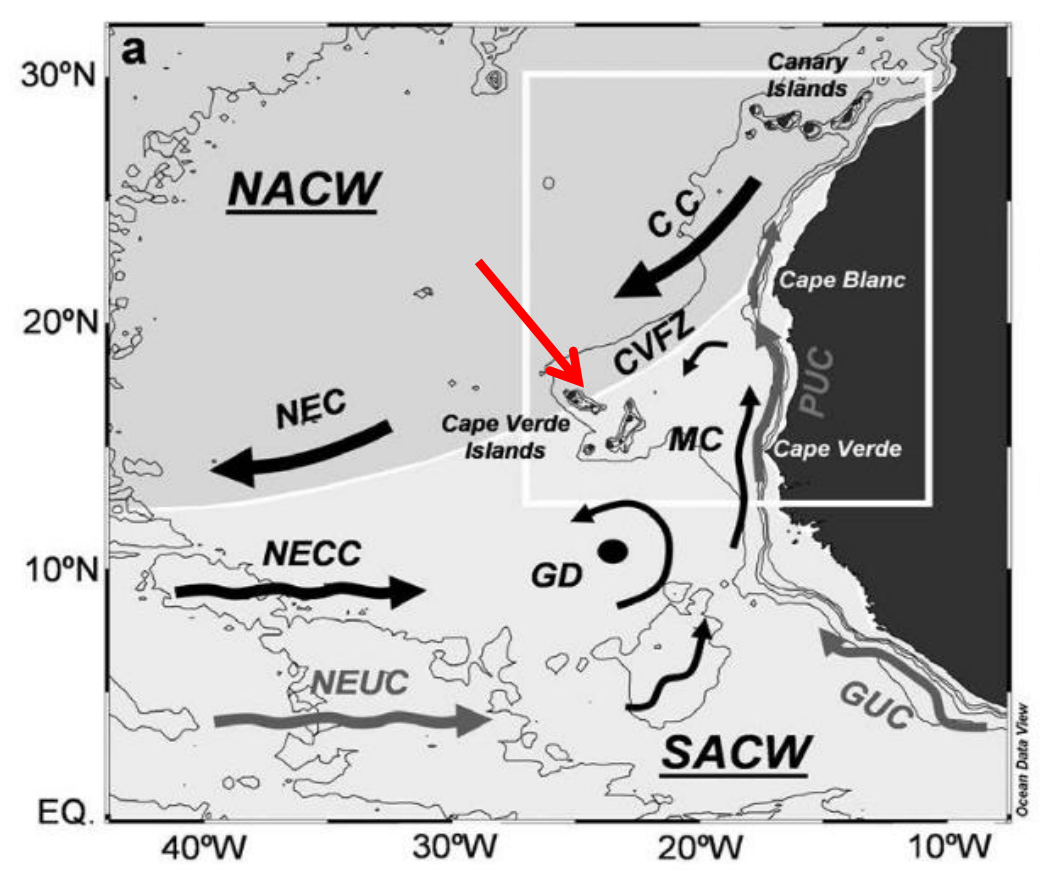

Figure S5 

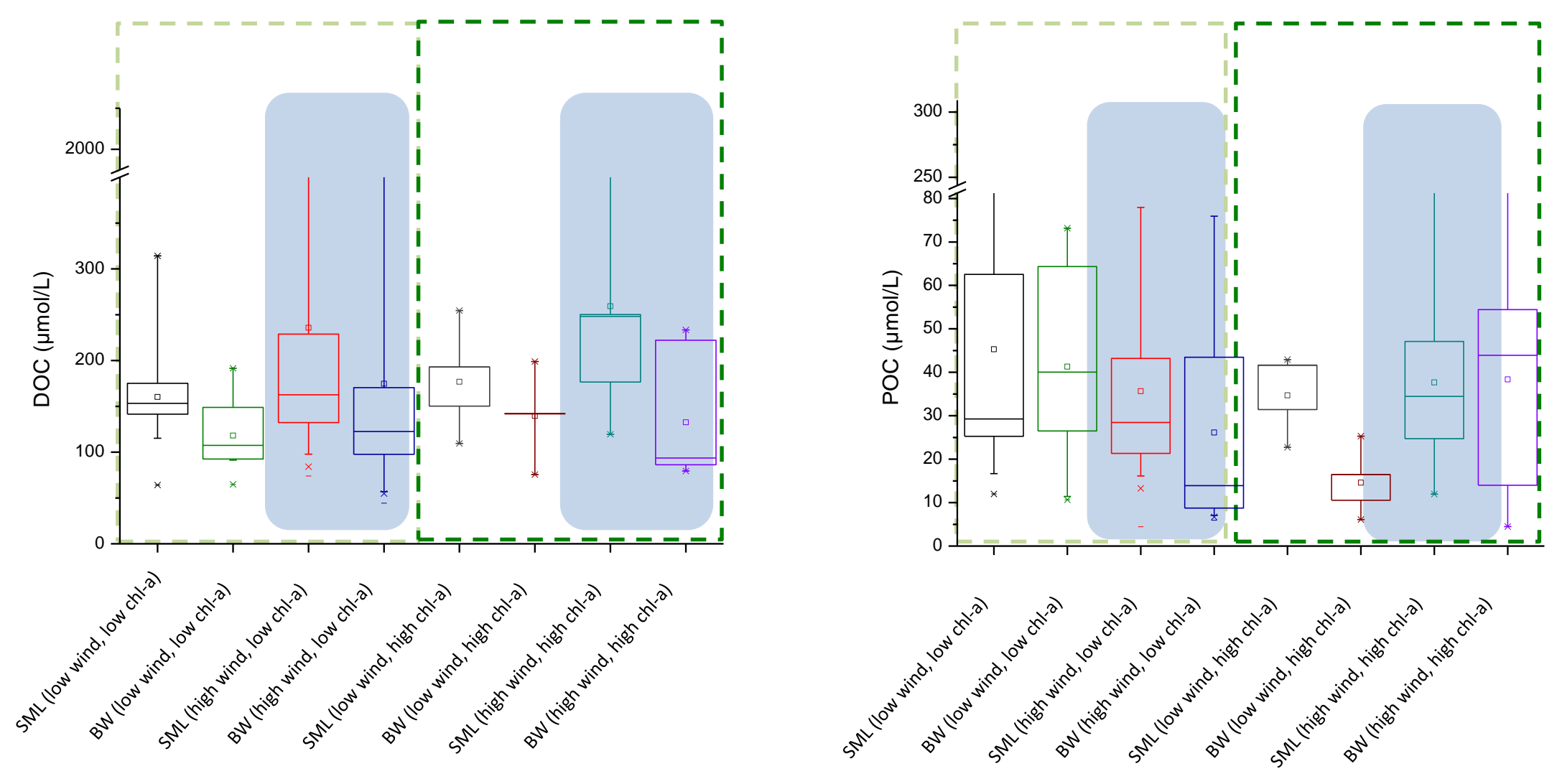

Figure 3 


\section{SML thickness}

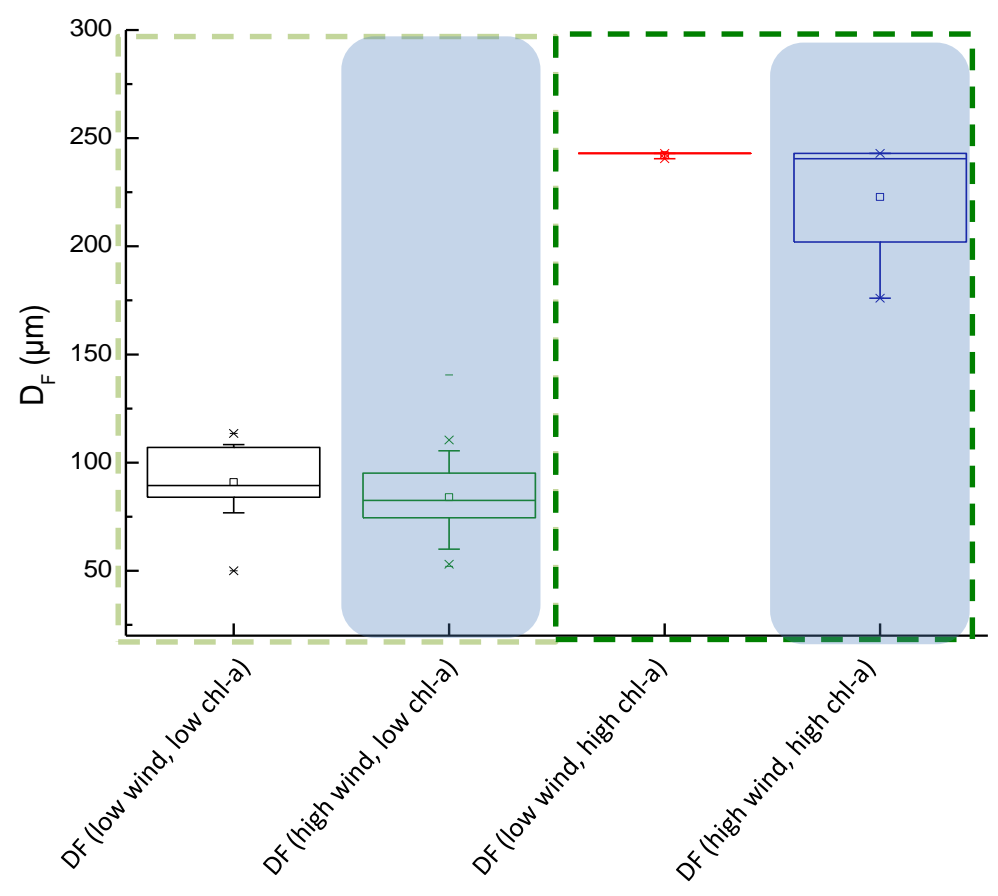

Figure 4 


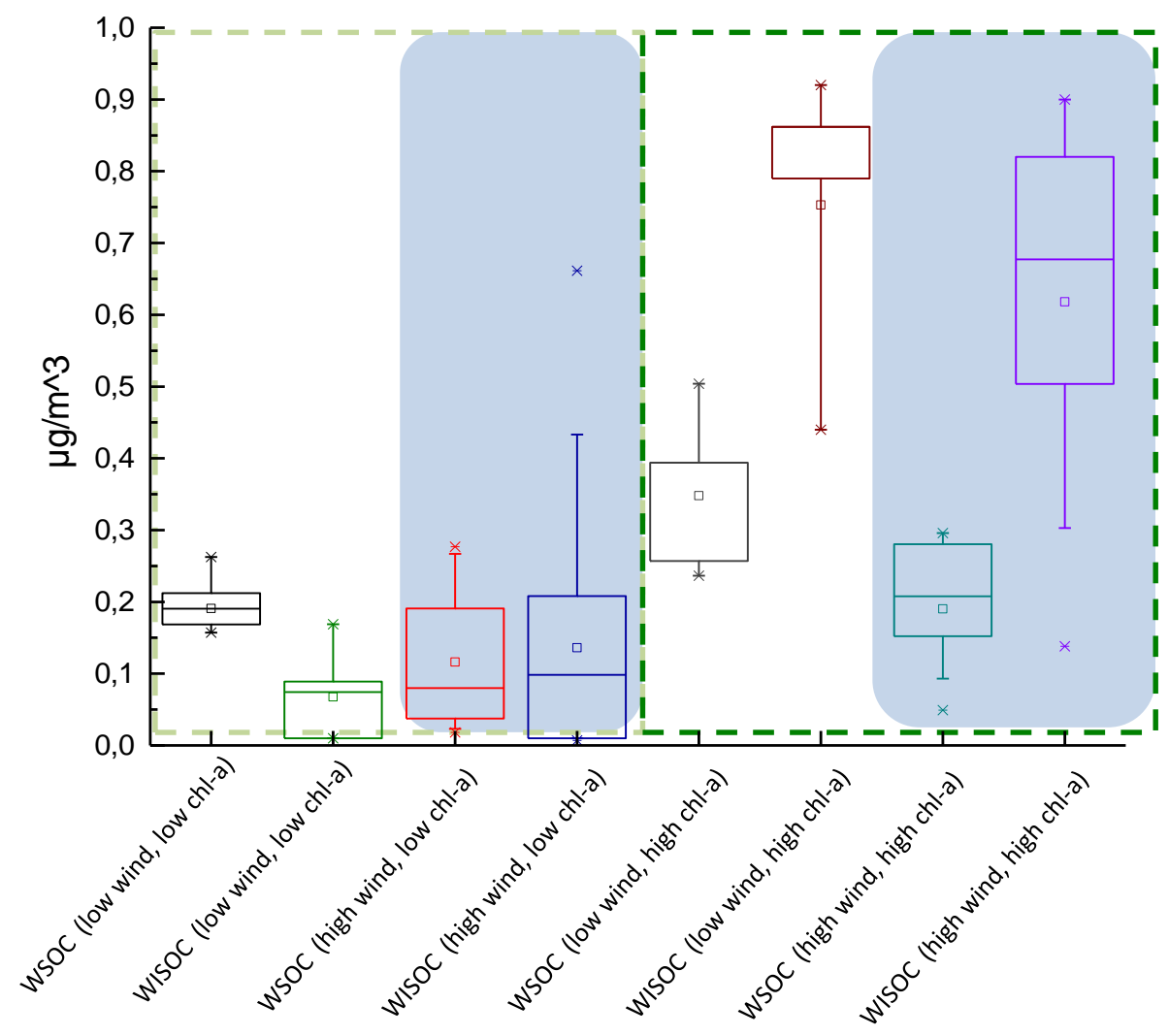

Figure 5 


\section{FINAL}

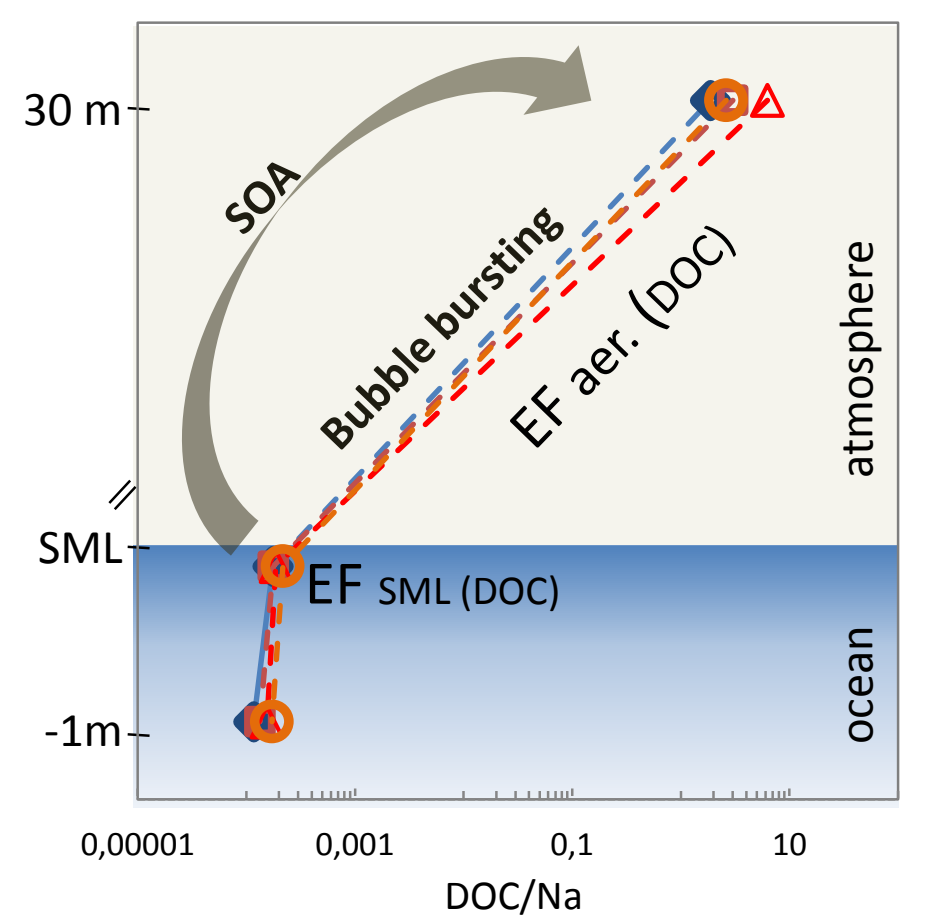

low wind, low chl-a

- $\mathrm{-}$ - high wind low chl-a $30 \mathrm{~m}$ -

- $\Delta$ - low wind, high chl-a

- - high wind, high chl-a

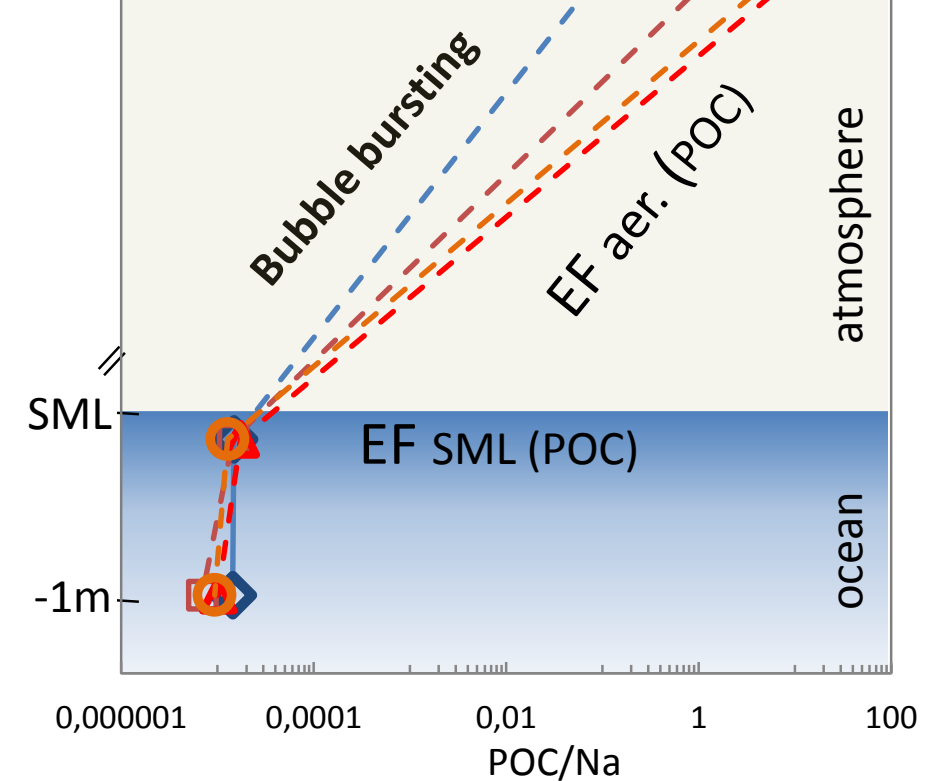

(a)

(b) 


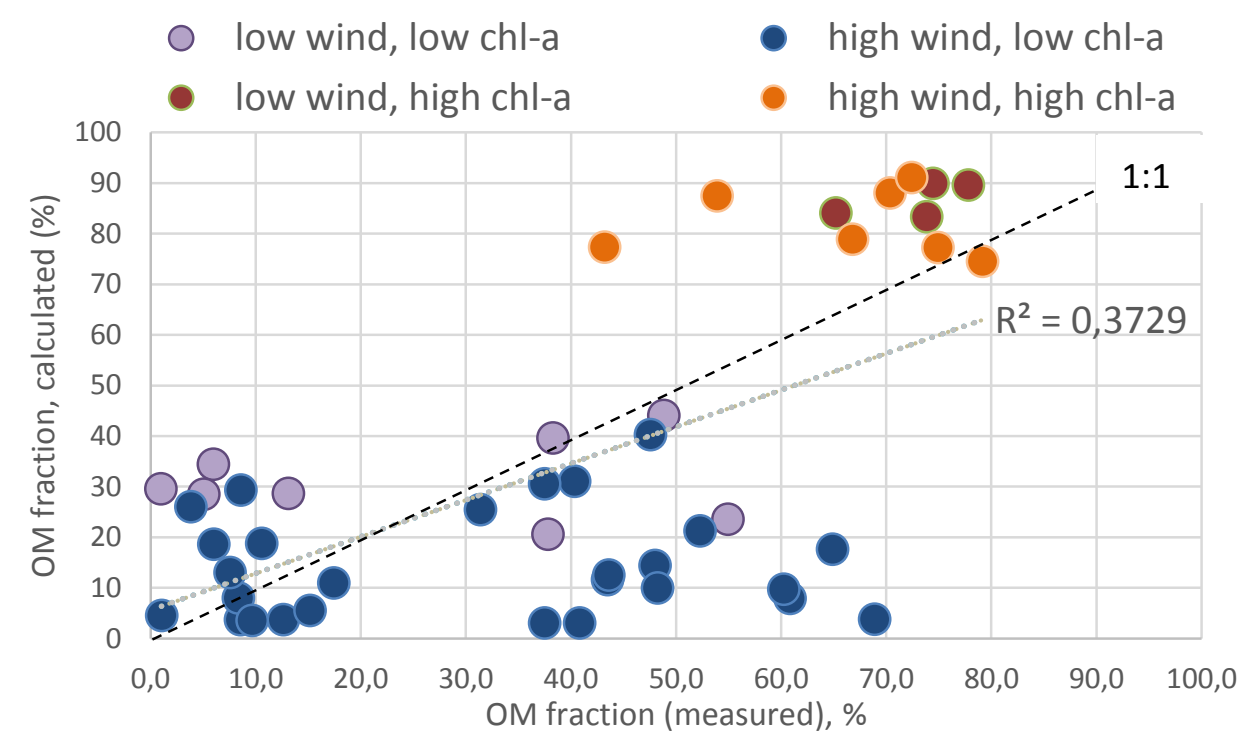

Figure 7 


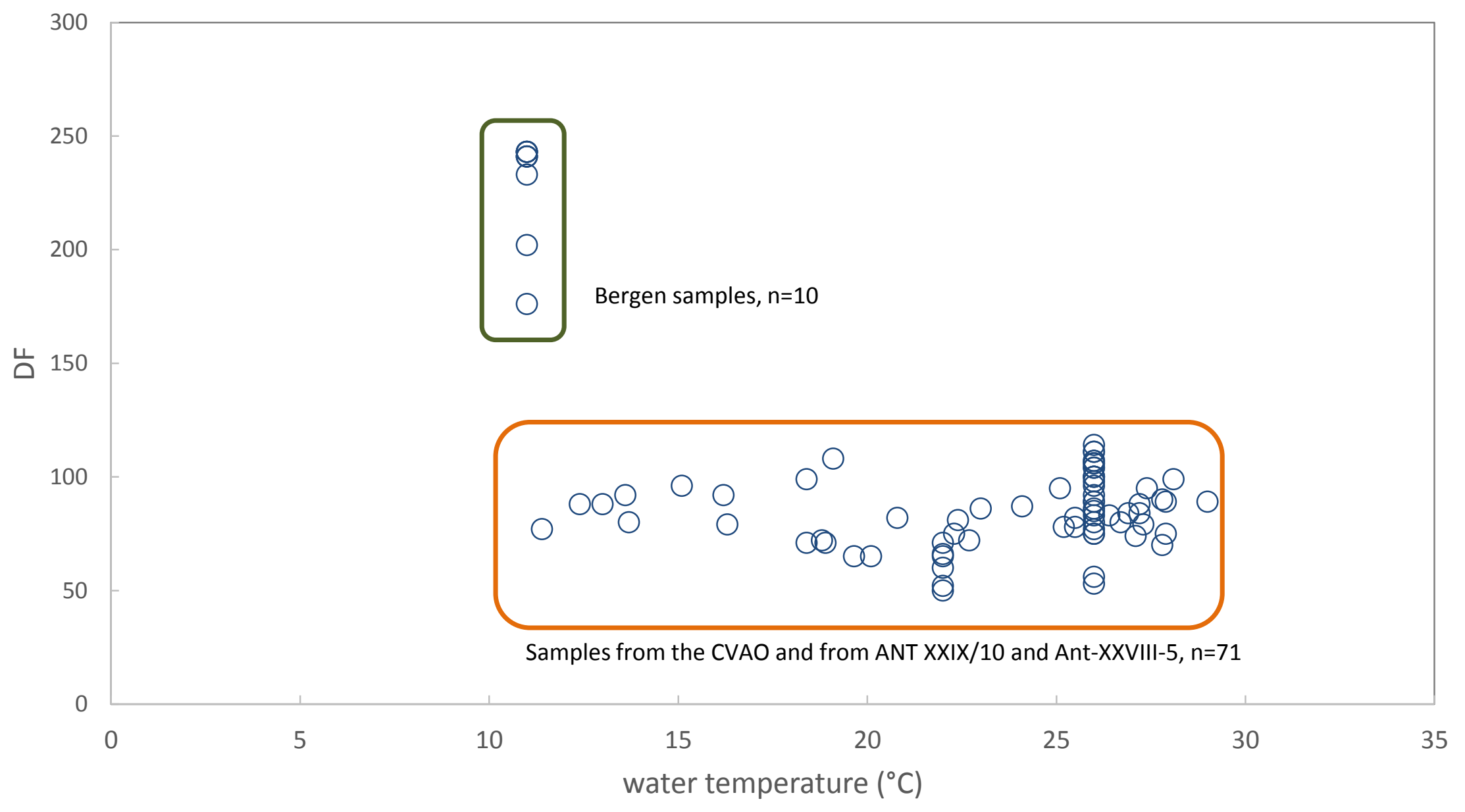

Figure S4 


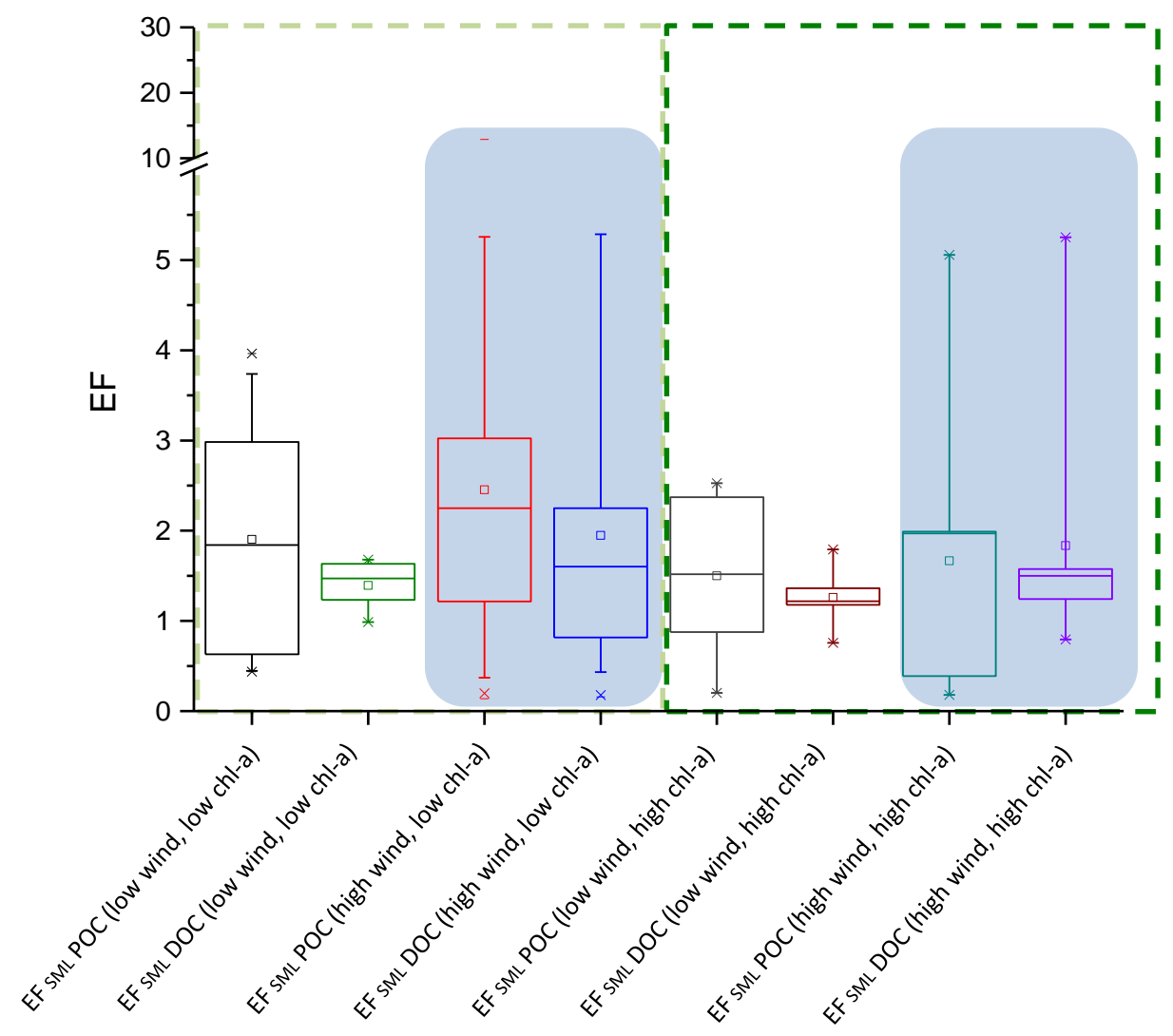

Figure S3 


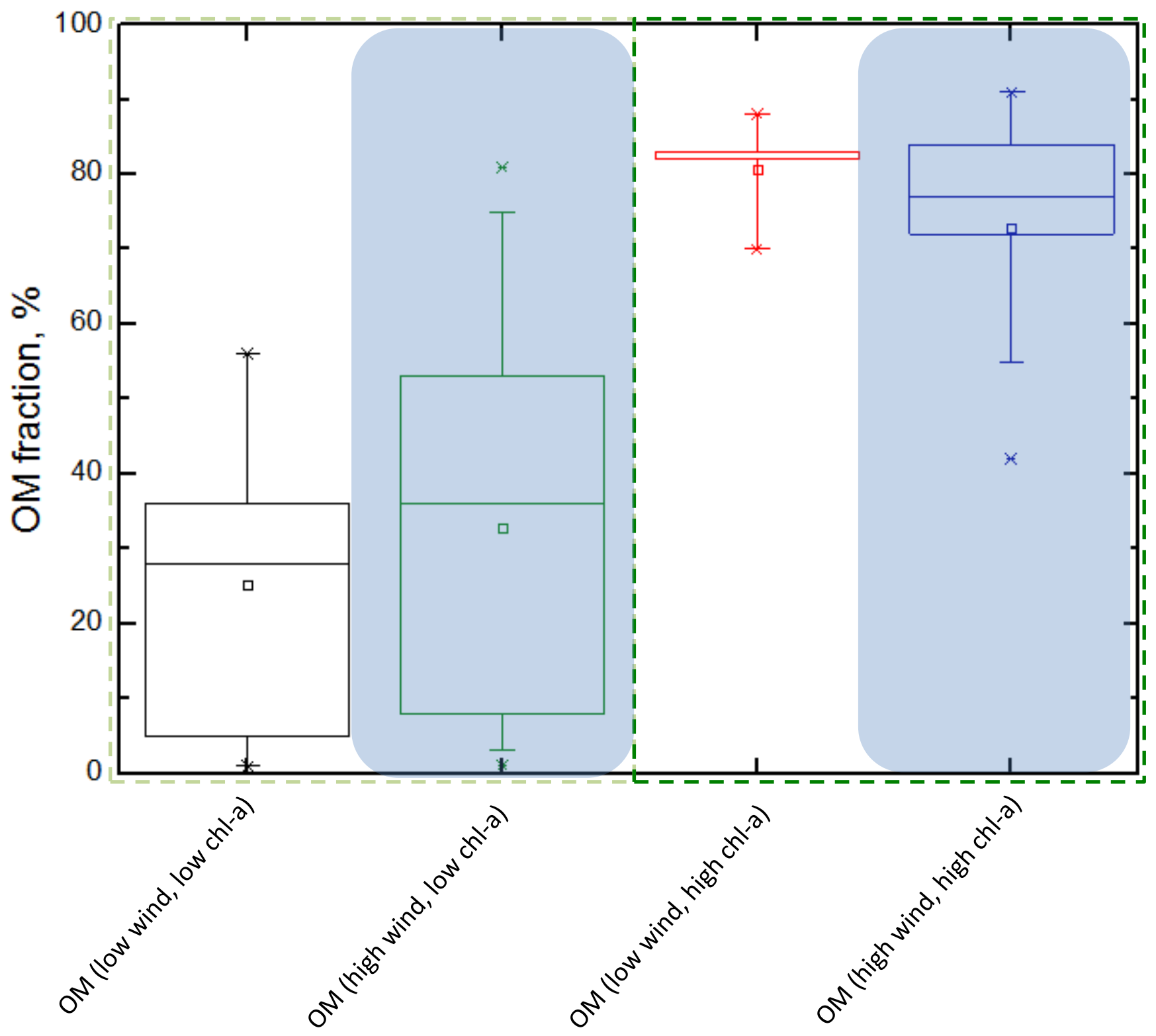




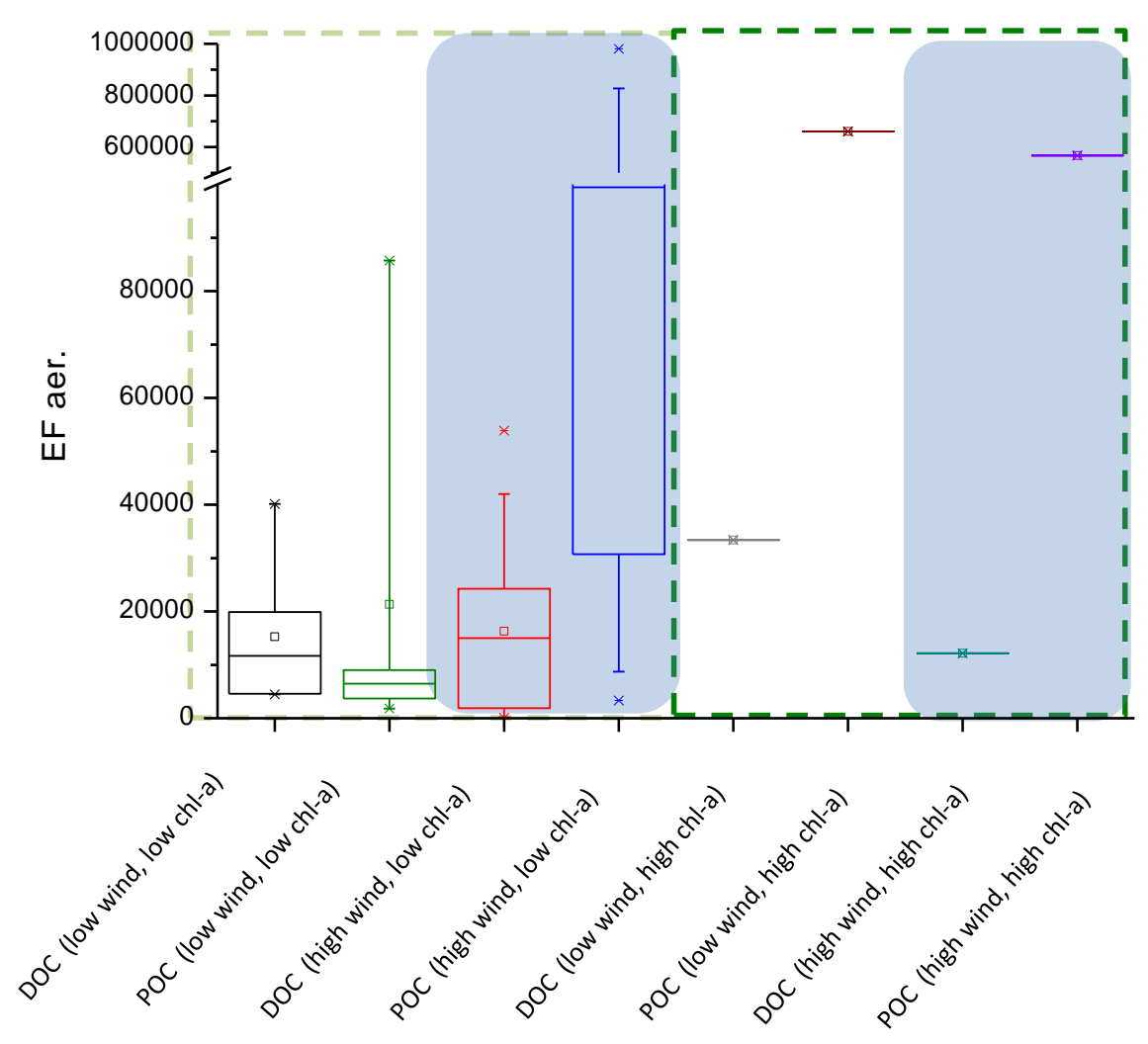

Figure S10 


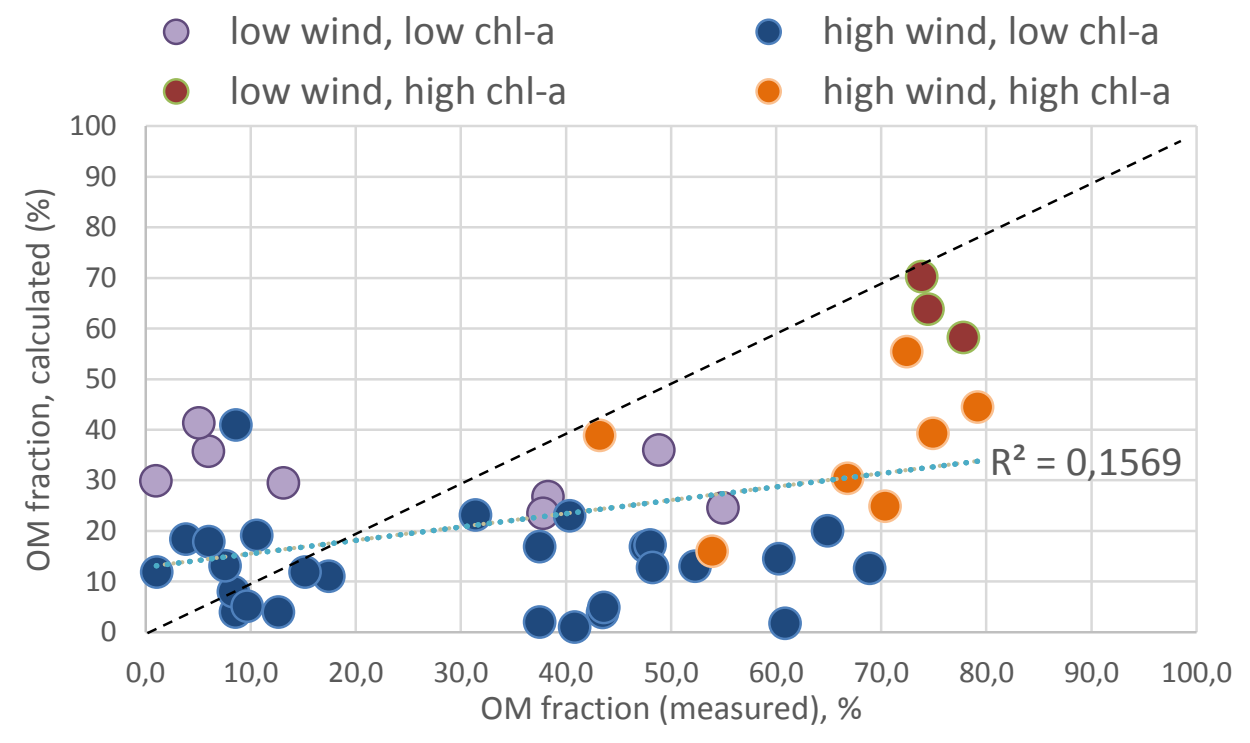

Fig. S8 neu 